\title{
Editorial: Environmental Stress-Promoting Responses in Algae
}

\author{
Koji Mikami $^{{ }^{*}}$, Susumu Takio ${ }^{2}$, Yuji Hiwatashi ${ }^{1}$ and Manoj Kumar ${ }^{3}$ \\ ${ }^{1}$ Department of Integrative Studies of Plant and Animal Production, School of Food Industrial Sciences, Miyagi University, \\ Sendai, Japan, ${ }^{2}$ Center for Water Cycles, Marine Environment, and Disaster Management, Kumamoto University, \\ Kumamoto, Japan, ${ }^{3}$ Climate Change Cluster, Faculty of Science, University of Technology Sydney, Sydney, NSW, Australia
}

Keywords: algae, environmental stress, stress tolerance, reproduction, life cycle

\section{Editorial on the Research Topic}

\section{Environmental Stress-Promoting Responses in Algae}

OPEN ACCESS

Edited by:

Valerio Matozzo,

University of Padua, Italy

Reviewed by:

Gergely Maroti,

Hungarian Academy of Sciences

(MTA), Hungary

Jan de Vries,

University of Göttingen, Germany

*Correspondence:

Koji Mikami

mikamik@myu.ac.jp

Specialty section:

This article was submitted to

Aquatic Physiology,

a section of the journal

Frontiers in Marine Science

Received: 19 October 2021 Accepted: 04 November 2021 Published: 25 November 2021

Citation:

Mikami K, Takio S, Hiwatashi Y and Kumar M (2021) Editorial:

Environmental Stress-Promoting

Responses in Algae.

Front. Mar. Sci. 8:797613.

doi: 10.3389/fmars.2021.797613
Algae live in the hydrosphere, where they experience fluctuations in temperature, salinity, nutrient levels, and sunlight, as well as other environmental stresses (Kumar et al., 2014; Raven and Giordano, 2014). The various responses involved in stress tolerance allow the algae to acclimate to these diverse environmental stresses (Flores-Molina et al., 2014; Kishimoto et al., 2019; Omuro et al., 2021). For example, algae vary their growth and reproduction under stress conditions as a tolerance mechanism to help survive disadvantageous conditions (Helmuth and Hofmann, 2001; Eckersley and Scrosati, 2012; Nayaka et al., 2017). Changes in gene expression also have essential functions in adaptive responses to stress. Moreover, each environmental stress promotes the expression of cognate sets of genes; therefore, stress responses can be recognized based on global changes in the stress-inducible accumulation of newly synthesized proteins and metabolites (Collén et al., 2007; Dittami et al., 2009; Cao et al., 2017; Sun et al., 2019; Rugiu et al., 2020). However, in contrast to the well-studied stress responses of land plants, little is known about the mechanisms regulating these physiological responses and the functions of the accumulated proteins and metabolites in algae. To address this knowledge gap, it is necessary to explore the physiological and molecular mechanisms of the stress-dependent regulation of growth, morphogenesis, gene expression, and metabolite biosynthesis in algae and how they affect biological, molecular, and biochemical levels. The resulting information will help us understand the responses of algae to environmental stress, which might distinct in part from those in land plants. Indeed, current studies on stress responses in streptophyte algae represented the differences in functions of conserved components of stress signaling networks between land plants and algae (Fürst-Jansen et al., 2020).

This Research Topic aims to establish an integrated view of how micro- and macroalgae regulate the physiological events involved in stress acclimation. Various aspects of the physiological responses of algae to environmental stress are reviewed, such as reproduction, growth, energy metabolism, and microbe-dependent responses in macroalgae, and gene expression, photosynthesis, and metabolite accumulation in microalgae. Recent physiological studies have indicated that abiotic stresses promote the transition from growth to the sexual and asexual reproductive phases (Liu et al., 2017). Suda and Mikami obtained novel findings about the effects of wounding and heat stress on the reproduction of thalli of the red alga Pyropia yezoensis (recently re-classified as Neopyropia yezoensis). In these algae, wounding promotes sexual and asexual reproduction, and heat stress induces callus production as a form of asexual reproduction. These findings demonstrate that the gametophytic thalli of $P$. yezoensis respond to environmental stress by resetting the timing of reproduction, in a phenomenon known as the life cycle trade-off (Liu et al., 2017). 
Algae commonly experience changes in salinity (Kirst, 1989; Karsten, 2012; Kumar et al., 2014). To explore responses to this common stress, Wen et al. performed a data-independent acquisition quantitative proteomic analysis of salinity-stressed Pyropia haitanensis. The abundances of proteins associated with the glycolytic pathway, the tricarboxylic acid cycle, and the pentose phosphate pathway varied under hypersaline conditions, indicating that salinity stress alters energy metabolism in $P$. haitanensis. Identifying protein biomarkers for salinity stress provided new knowledge that may enable efforts to develop salttolerant seaweed cultivars. In addition, Endo et al. investigated the accumulation of nitrogen in meristems of the brown alga Eisenia bicyclis, showing that the breakdown of blades due to heat stress promoted nitrogen accumulation in meristems in the lower part of the blade, which in turn promoted the intercalary growth of the algae. Moreover, Xu et al. demonstrated that the coccolithophore Emiliania huxleyi acclimates to lowsalinity stress by upregulating photosynthetic performance under conditions that replicate ocean acidification. These findings suggest that macro- and micro-algae have a variety of stressdependent mechanisms to tolerate the negative impacts of environmental stresses.

Various types of environmental stress cause cellular damage in photosynthetic organisms via the production of reactive oxygen species (ROS) such as superoxide anion $\left(\mathrm{O}_{2}^{-}\right)$and hydrogen peroxide $\left(\mathrm{H}_{2} \mathrm{O}_{2}\right)$ (Kumar et al., 2014; Choudhury et al., 2017; Hasanuzzaman et al., 2020). These algae have evolved ROS-scavenging systems to adapt to these stresses and protect their photosynthetic machinery (Mittler et al., 2011; Hasanuzzaman et al., 2020). Using a reverse-genetics approach, Lee et al. determined that the early light-inducible protein ELIP3 protects the green microalga Chlamydomonas reinhardtii from high-light- and cold-induced photooxidative damage to the photosynthetic machinery and enhances survival of these algae. In addition, Kumari et al. revealed that volatile organic

\section{REFERENCES}

Cao, M., Wang, D., Mao, Y., Kong, F., Bi, G., Xing, Q., et al. (2017). Integrating transcriptomics and metabolomics to characterize the regulation of EPA biosynthesis in response to cold stress in seaweed Bangia fuscopurpurea. PLoS ONE 12, e0186986. doi: 10.1371/journal.pone. 0186986

Choudhury, F. K., Rivero, R. M., Blumwald, E., and Mittler, R. (2017). Reactive oxygen species, abiotic stress and stress combination. Plant J. 90, 856-867. doi: $10.1111 /$ tpj.13299

Collén, J., Guisle-Marsollier, I., Léger, J. J., and Boyen, C. (2007). Response of the transcriptome of the intertidal red seaweed Chondrus crispus to controlled and natural stresses. New Phytol. 176, 45-55. doi: 10.1111/j.1469-8137.2007.02152.x

Dittami, S. M., Scornet, D., Petit, J. L., Ségurens, B., Da Silva, C., Corre, E., et al. (2009). Global expression analysis of the brown alga Ectocarpus siliculosus (Phaeophyceae) reveals large-scale reprogramming of the transcriptome in response to abiotic stress. Genome Biol. 10, R66. doi: 10.1186/gb-2009-10-6-r66

Eckersley, L. K., and Scrosati, R. A. (2012). Temperature, desiccation, and species performance trends along an intertidal elevation gradient. Curr. Dev. Oceanogr. 5, 59-73. doi: 10.31230/osf.io/y9ph3

Egan, S., Harder, T., Burke, C., Steinberg, P., Kjelleberg, S., and Thomas, T. (2013). The seaweed holobiont: understanding seaweed-bacteria interactions. FEMS Microbiol. Rev. 37, 462-476. doi: 10.1111/1574-6976.12011 compounds (specifically long-chain fatty aldehydes and fatty alcohols) function as chemical messengers to scavenge ROS in the arachidonic acid-accumulating microalga Lobosphaera incisa under nitrogen-deficient conditions. Finally, Singh et al. uncovered the roles of tocopherols as antioxidant molecules in the Selenastraceae algae Monoraphidium sp. under low-nutrient conditions. These findings highlight the critical roles of ROS scavenging in environmental stress responses in algae.

Microbe-seaweed interactions are critical for regulating algal development, as some algae acquire morphogenesispromoting factors from bacteria (Egan et al., 2013; Singh and Reddy, 2014; Wichard et al., 2015). Ghaderiardakani et al. described an additional important aspect of this interaction: the involvement of microbes in the growth and development of healthy algae under various environmental stress conditions. These findings provide new insight into the survival of algae under stress conditions in the hydrosphere.

In conclusion, this Research Topic highlights novel findings that significantly increase our understanding of how stressinducible responses operate and their effects on gene expression, the production of functional molecules, reproduction, and survival in algae.

\section{AUTHOR CONTRIBUTIONS}

All authors listed have made a substantial, direct, and intellectual contribution to the work and approved it for publication.

\section{ACKNOWLEDGMENTS}

We thank all authors who submitted their work for this Research Topic, as well as the reviewers for their invaluable help with manuscript evaluation and the professional editorial staff at Frontiers for their support.

Flores-Molina, M. R., Thomas, D., Lovazzano, C., Nunez, A., Zapata, J., Kumar, M., et al. (2014). Desiccation stress in intertidal seaweeds: effects on morphology, photosynthetic performance and antioxidant responses. Aquat. Bot. 113, 90-99. doi: 10.1016/j.aquabot.2013.11.004

Fürst-Jansen, J. M. R., de Vries, S., and de Vries, J. (2020). Evo-physio: on stress responses and the earliest land plants. J. Exp. Bot. 71, 3254-3269. doi: $10.1093 /$ jxb/eraa007

Hasanuzzaman, M., Bhuyan, M. H. M. B., Parvin, K., Bhuiyan, T. F., Anee, T. I., Nahar, K., et al. (2020). Regulation of ROS metabolism in plants under environmental stress: a review of recent experimental evidence. Int. J. Mol. Sci. 21, 8695. doi: 10.3390/ijms21228695

Helmuth, B. S., and Hofmann, G. E. (2001). Microhabitats, thermal heterogeneity, and patterns of physiological stress in the rocky intertidal zone. Biol. Bull. 201, 374-384. doi: $10.2307 / 1543615$

Karsten, U. (2012). "Seaweed acclimation to salinity and desiccation stress," in Seaweed Biology: Novel Insights into Ecophysiology, Ecology and Utilization. Ecological Studies, Vol. 219, eds C. Wiencke and K. C. Bischof (Berlin, Heidelberg: Springer-Verlag), 87-107. doi: 10.1007/978-3-642-28451-9_5

Kirst, G. O. (1989). Salinity tolerance of eukaryotic marine algae. Annu. Rev. Plant Physiol. Plant Mol. Biol. 40, 21-53. doi: 10.1146/annurev.pp.41.060190.000321

Kishimoto, I., Ariga, I., Itabashi, Y., and Mikami, K. (2019). Heat-stress memory is responsible for acquired thermotolerance in Bangia fuscopurpurea. J. Phycol. 55, 971-975. doi: 10.1111/jpy.12895 
Kumar, M., Kumari, P., Reddy, C. R. K., and Jha, B. (2014). "Salinity and desiccation induced oxidative stress acclimation in seaweeds," in Advances in Botanical Research: Vol. 71. Sea Plants (New York, NY: Academic Press), 91-124.

Liu, X., Bogaert, K., Engelen, A. H., Leliaert, F., Roleda, M. Y., and De Clerck, O. (2017). Seaweed reproductive biology: environmental and genetic controls. Bot. Mar. 60, 89-108. doi: 10.1515/bot-2016-0091

Mittler, R., Vanderauwera, S., Suzuki, N., Miller, G., Tognetti, V. B., Vandepoele, K., et al. (2011). ROS signaling: the new wave? Trends Plant Sci. 16, 300-309. doi: 10.1016/j.tplants.2011.03.007

Nayaka, S., Toppo, K., and Verma, S. (2017). "Adaptation in algae to environmental stress and ecological conditions," in Plant Adaptation Strategies in Changing Environment, eds V. Shukla, S. Kumar, and N. Kumar (Berlin; Heidelberg: Springer), 103-115.

Omuro, Y., Khoa, H. V., and Mikami, K. (2021). The absence of hydrodynamic stress promotes acquisition of freezing tolerance and freeze-dependent asexual reproduction in the red alga 'Bangia' sp. ESS1. Plants 10, 465. doi: 10.3390/plants10030465

Raven, J., and Giordano, M. (2014). Algae. Curr. Biol. 24, R591. doi: 10.1016/j.cub.2014.05.039

Rugiu, L., Panova, M., Pereyra, R. T., and Jormalainen, V. (2020). Gene regulatory response to hyposalinity in the brown seaweed Fucus vesiculosus. BMC Genomics 21, 42. doi: 10.1186/s12864-020-6470-y

Singh, R., and Reddy, C. (2014). Seaweed-microbial interactions: key function of seaweed-associated bacteria. FEMS Microbiol. Ecol. 88, 213-230. doi: 10.1111/1574-6941.12297
Sun, P., Tang, X., Bi, G., Xu, K., Kong, F., and Mao, Y. (2019). Gene expression profiles of Pyropia yezoensis in response to dehydration and rehydration stresses. Mar. Genomics 43, 43-49. doi: 10.1016/j.margen.2018. 09.005

Wichard, T., Charrier, B., Mineur, F., Bothwell, J. H., de Clerck, O., and Coates, J. C. (2015). The green seaweed Ulva: a model system to study morphogenesis. Front. Plant Sci. 6, 72. doi: 10.3389/fpls.2015.00072

Conflict of Interest: The authors declare that the research was conducted in the absence of any commercial or financial relationships that could be construed as a potential conflict of interest.

Publisher's Note: All claims expressed in this article are solely those of the authors and do not necessarily represent those of their affiliated organizations, or those of the publisher, the editors and the reviewers. Any product that may be evaluated in this article, or claim that may be made by its manufacturer, is not guaranteed or endorsed by the publisher.

Copyright (c) 2021 Mikami, Takio, Hiwatashi and Kumar. This is an open-access article distributed under the terms of the Creative Commons Attribution License (CC $B Y)$. The use, distribution or reproduction in other forums is permitted, provided the original author(s) and the copyright owner(s) are credited and that the original publication in this journal is cited, in accordance with accepted academic practice. No use, distribution or reproduction is permitted which does not comply with these terms. 